\title{
Simultaneous Resection For Colon Cancer and Synchronous Liver Metastases. Case Series With Follow-Up
}

\author{
Resección Simultánea por Cáncer de Colon y Metástasis Hepáticas \\ Sincrónicas. Serie de Casos con Seguimiento
}

Carlos Manterola ${ }^{1,2} \&$ Nataniel Claros $^{3}$

\begin{abstract}
MANTEROLA, C. \& CLAROS, N. Simultaneous resection for colon cancer and synchronous liver metastases. Case series with follow-up. Int. J. Morphol., 39(6):1763-1768, 2021.

SUMMARY: Treatment of colonic cancer (CC) and synchronic liver metastasis (SLM) is still controversial in relation to how to act. The aim of this study was to analyze initial single center experience in simultaneous surgical approach of patients with CC and SLM, in terms of overall survival (OS) and disease-free survival (DFS). Retrospective case series of patients with CC and SLM undergoing simultaneous surgery, consecutively, at Clínica RedSalud Mayor Temuco, between 2007 and 2021. Outcome variables were OS and DFS. Other variables of interest were postoperative morbidity (POM), surgical time, hospital stay and mortality. Descriptive statistics was used (measures of central tendency and dispersion), and survival analysis was estimated applying Kaplan Meier curves. Sixteen patients (10 female and 6 male) were operated, with a median age of 61 years. The most frequent localization was cecum and right colon (37.5\%). In all patients some type of liver resection was added (parenchymal-sparing hepatectomy or anatomical resection). Median surgical time and hospital stay were $150 \mathrm{~min}$ and 5 days respectively. POM was $31.2 \%$ (5 cases), mainly Clavien \& Dindo I and II (12.5 $\%$ of patients required a re-intervention). With a median follow-up of 52 months 1, 3 and 5-year OS were $100 \%, 62.5 \%$, and $50.0 \%$ respectively. On the other hand, DFS rates of 1, 3 and 5-year were $75.0 \%, 43.8 \%$, and $25.0 \%$ respectively. The series had no mortality. OS, DFS, POM and mortality, were like other series. Simultaneous resection of CC and SLM is an aggressive approach, but not compromise oncological outcomes.
\end{abstract}

KEY WORDS: "Colonic Neoplasms"[Mesh]; "Colonic Neoplasms/surgery"[Mesh]; "Lymph Node Excision"[Mesh]; "Sigmoid Neoplasms"[Mesh]); Liver Neoplasms / surgery.

\section{INTRODUCTION}

Colorectal cancer has become the 3rd most common malignancy worldwide (Ferlay et al., 2019). In Chile, adjusted mortality rate for colon cancer (CC) in 2010, for women and men was 7.6 and 9.1 x 100,000 inhabitants respectively, with an increase of $2 \%$ points respecting to a similar measurement in 1990 (Itriago et al, 2013).

On the other hand, liver metastases (LM), are still one of the main causes of death in patients with CC (Abreu et al., 2020; De Raffele et al., 2020; Zhai et al., 2021), and synchronous liver metastases (SLM) in CC, are present between 15-25\% of initially diagnosed patients (Lykoudis et al., 2014; Silberhumer et al., 2015; De Raffele et al.; Zhai et al.).

There are 4 treatment strategies for SLM of CC: resection of $\mathrm{CC}$ followed by chemotherapy (CT); and then liver resection (LR), 3-6 months later (provided that LM are still resectable). Simultaneous resection of CC and LM. Liver first, or 3-6 cycles neoadjuvant CT, followed by LR, adjuvant $\mathrm{CT}$, and $\mathrm{CC}$ resection (more appropriate in patients with asymptomatic $\mathrm{CC}$ and unresectable or marginally resectable LM). And, LR followed by adjuvant $\mathrm{CT}$, resection of CC and adjuvant CT (for patients with asymptomatic CC and resectable LM) (Ihnát et al., 2015).

Five-year overall survival (OS) of surgically treated patients with CC may vary between $40 \%$ to $85 \%$ (IVa to IIa stages) (Kwaan et al., 2013; Renouf et al., 2013; Manterola \& Claros, 2021); but in cases of CC with SLM (CCSLM), 5-year OS rate is usually around $20 \%$ (Grytsenko, 2020), what may improve to $30 \%$ or more,

\footnotetext{
${ }^{1}$ Department of Surgery and Center for Morphological and Surgical Studies (CEMyQ), Universidad de La Frontera, Chile.

${ }^{2}$ Clínica RedSalud Mayor, Temuco, Chile.

${ }^{3}$ Hospital Obrero N ${ }^{\circ} 1$, Caja Nacional de Salud, La Paz, Bolivia.
} 
when surgery is followed by adjuvant systemic chemotherapy regimens such as FOLFOX, FOLFIRI, XELOX with or without targeted agents (Robinson et al., 2011; Ferretti et al., 2015; Zhai et al.).

The only potentially curative treatment for CCSLM, is surgical resection (Xu et al., 2011; Olsson et al., 2021), associated to adjuvant chemotherapy, which has a median overall survival (OS) of 47.3 months and 5-year OS of 31 $\%$, which is superior to non-surgical treatment: 17.2 months and $4 \%$ respectively (Zhai et al.).

The aim of this study was to determine OS and disease-free survival (DFS) in patients with CCSLM surgically treated.

\section{MATERIAL AND METHOD}

The report of this study was written based on the MInCir Declaration for the reporting of descriptive observational studies (Manterola \& Otzen, 2017).

Study design: Case series with follow-up.

Setting: The study was conducted at Clínica RedSalud Mayor Temuco. The recruitment period was between January 2007 and June 2020. Minimum follow-up was 12 months. Participants: Patients operated for CCSLM, undergoing colectomy with lymph nodal dissection with oncological criteria and liver resection; consecutively; in the period and institution indicated above, by the first author (CM). Palliative surgery cases and those who received neoadjuvant treatment were excluded.

Sample size: Since this is an observational and descriptive study, no sample size was estimated.

Variables: The outcome variables were OS and DFS. Other variables of interest were postoperative morbidity (POM), measured up to 30 days after surgery, applying the Clavien \& Dindo proposal (Clavien et al., 2009); tumor location (CC and LM), type of surgery, and operative mortality.

Follow-up protocol: After hospital discharge, all patients were followed up with strict controls at least at months 1 , 3 and 6; and after that once a year. During controls, a clinical evaluation, general laboratory and computed tomography of the abdomen and pelvis were realized. In addition, information on death certificates obtained from the Civil Registry and Identification was used, where necessary.
Statistical methods: Data collection was carried out and analyzed with the Stata 12.0 / SE® program. Descriptive statistics was used, applying measures of central tendency and dispersion (medians, minimum and maximum values). OS was calculated applying Kaplan-Meier method and the comparison of curves was studied applying the log-rank test.

Biases: These were reduced with a masked data collection and a complete follow-up of the patients that make up this series for at least 12 months (the last patient recruited).

Ethics: Ethical guidelines for research defined by the Declaration of Helsinki (Helsinki, 2013), were observed. All patients gave their informed consent in writing.

\section{RESULTS}

During the study period, 16 patients were operated for CCSLM, with a median age of 61 (53-84) years, $62.5 \%$ of which were female. $87.5 \%$ of the series had some type of comorbidity (Tables I and II).

The most frequent location of the primary lesions was cecum-colon ( 6 cases, $37.5 \%$ ) and sigmoid (5 cases, $31.3 \%$ ). With $100 \%$ resectability of the series, it was the right colectomy, the most frequently used technique (Fig. 1 and Table I). On the other hand, unilobar was the most frequent location of LM (11 cases, $68.8 \%$ ), and most cases presented one or two LM $(75.0 \%)$. Left hepatectomies were the most frequently used technique ( 7 cases, $43.8 \%$ ) (Fig. 2 and Table I).

The medians of the surgical time, preoperative CEA levels, and hospital stance were $150 \mathrm{~min}, 98.5(\mathrm{ng} / \mathrm{ml})$ and 5 days respectively (Table II).

POM was $31.2 \%$ (5 cases), most of which were Clavien \& Dindo type I and II (5 cases, $31.3 \%$ ); 2 cases of anastomotic dehiscence stand out and a left ureteral injury. Both anastomotic leakages required reoperation and the ureteral injury was repaired during the primary operation (Table III). There was no operative mortality. (Table I)

All patients underwent some chemotherapy scheme

With a median follow-up of 52 months, median OS was 48 months. One, 3 and 5-year OS were $100 \%, 62.5$ $\%$, and $50.0 \%$ respectively (Fig. 3). On the other hand, DFS rates of 1, 3 and 5-year were $75.0 \%, 43.8 \%$, and $25.0 \%$ respectively (Fig. 3 ). 
Table I. Clinicopathological features of patients with CCSLM $(\mathrm{N}=16)$.

\begin{tabular}{|c|c|c|}
\hline Variable & $\mathrm{N}^{\circ}$ cases & $\%$ \\
\hline \multicolumn{3}{|l|}{ Sex } \\
\hline Female & 10 & 62.5 \\
\hline Male & 6 & 37.5 \\
\hline \multicolumn{3}{|l|}{ Comorbidity } \\
\hline None & 2 & 12.5 \\
\hline AHT & 8 & 50.0 \\
\hline II-DM & 2 & 12.5 \\
\hline $\mathrm{AHT}+\mathrm{II}-\mathrm{DM}$ & 4 & 25.0 \\
\hline \multicolumn{3}{|l|}{ Primary tumor } \\
\hline Cecum and right colon & 6 & 37.5 \\
\hline Transverse colon & 2 & 12.5 \\
\hline Left colon & 3 & 18.8 \\
\hline Sigmoid & 5 & 31.3 \\
\hline \multicolumn{3}{|l|}{ Type of colectomy } \\
\hline Right colect omy & 6 & 37.5 \\
\hline Right extended colectomy & 2 & 12.5 \\
\hline Left colectomy & 3 & 18.8 \\
\hline Sigmoidectomy & 5 & 31.3 \\
\hline \multicolumn{3}{|l|}{ Liver lesion distribution } \\
\hline Bilobar & 5 & 31.3 \\
\hline Left lobe & 7 & 37.5 \\
\hline Right lobe & 4 & 25.0 \\
\hline \multicolumn{3}{|l|}{ Number of LM } \\
\hline $1-2$ & 12 & 75.0 \\
\hline 3 or more & 4 & 25.0 \\
\hline \multicolumn{3}{|l|}{ Liver surgery } \\
\hline Parenchymal sparing & 5 & 31.3 \\
\hline Left hemihepatectomy & 2 & 12.5 \\
\hline Right hemihepatectomy & 4 & 25.0 \\
\hline Left lateral lobectomy & 5 & 31.3 \\
\hline \multicolumn{3}{|l|}{ Chemotherapy } \\
\hline Neoadjuvant & 5 & 31.2 \\
\hline Adjuvant & 11 & 68.8 \\
\hline
\end{tabular}

Table II. Postoperative morbidity in patients under study. $(\mathrm{N}=16)$

\begin{tabular}{lcc}
\hline Variable & Median & $\begin{array}{c}\text { Minimum - } \\
\text { Maximum }\end{array}$ \\
\hline Age (years) & 61 & $53-86$ \\
Diameter of LM (cm) & 4 & $2-9$ \\
Surgical time (min) & 150 & $120-230$ \\
Preoperative CEA levels (ng/ml) & 98.5 & $23-350$ \\
Hospital stance (days) & 5 & $5-6$ \\
Follow-up (months) & 52 & $18-77$
\end{tabular}

POM: Postoperative morbidity*: Ureteral injury was repaired in the course of the same intervention.
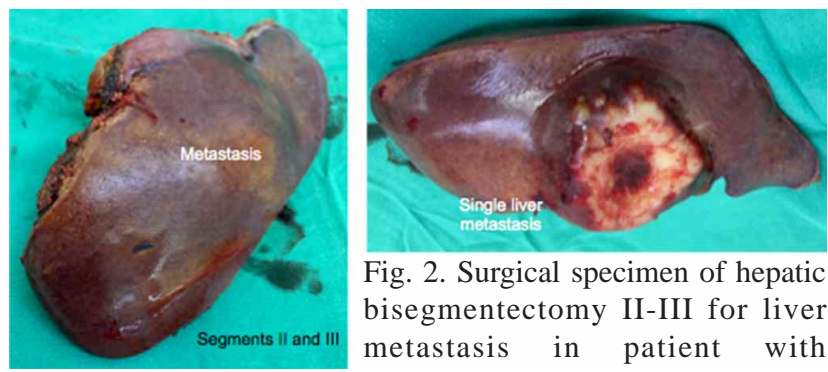

Fig. 2. Surgical specimen of hepatic bisegmentectomy II-III for liver metastasis in patient with simultaneous colon cancer.
Table III. Postoperative morbidity in patients under study. $(\mathrm{N}=16)$

\begin{tabular}{lcc}
\hline Variable & $\mathrm{N}^{\circ}$ cases & $\%$ \\
\hline POM & & \\
$\quad$ Present & 5 & 31.2 \\
$\quad$ Absent & 11 & 68.8 \\
POM etiology & & \\
$\quad$ Surgical site infection & 2 & 12.5 \\
$\quad$ Anastomotic leakage & 2 & 12.5 \\
$\quad$ Left ureteral injury * & 1 & 6.2 \\
POM according Clavien \& Dindo & & \\
I & 2 & 12.5 \\
II & 2 & 12.5 \\
IIIb & 1 & 6.2 \\
Reinterventions & & \\
Yes & 2 & 12.5 \\
No & 14 & 87.5 \\
\hline POM: Postop
\end{tabular}

POM: Postoperative morbidity * : Ureteral injury was repaired in the course of the same intervention.

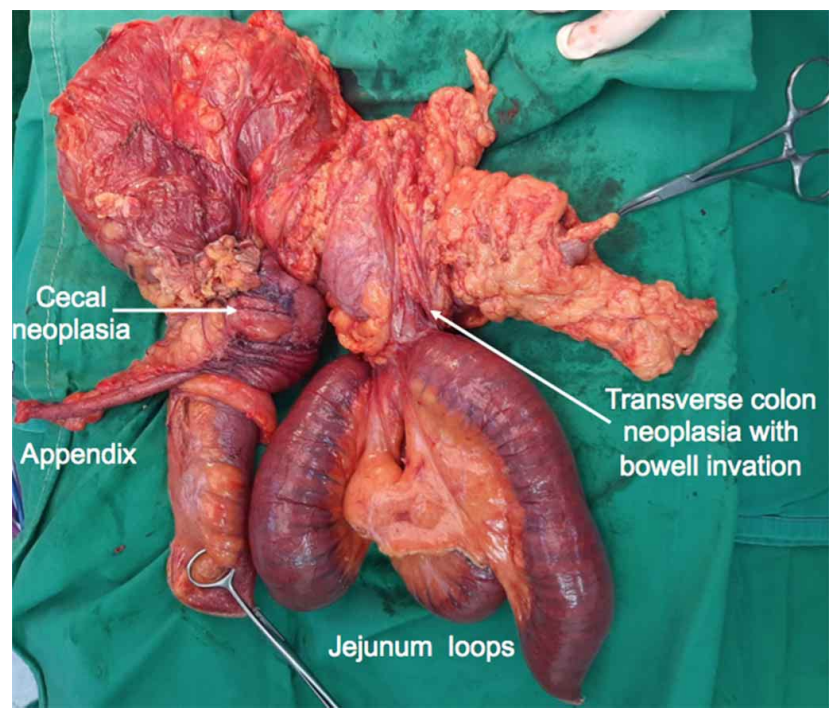

Fig. 1. Surgical specimen corresponding to a patient with simultaneous cancer of the cecum and transverse colon, with infiltration of abdominal wall (primary cecal tumor), and small bowel loops (primary transverse tumor), and a single liver me्stastasis in segments II and III.

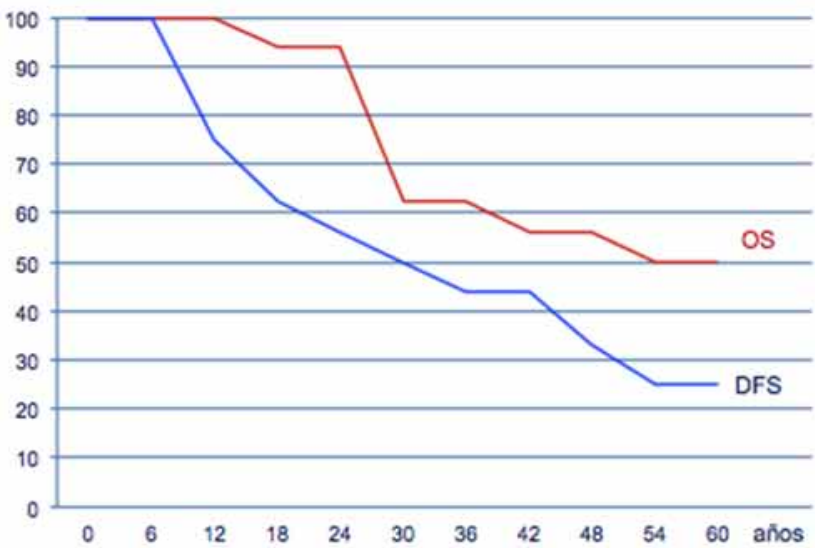

Fig. 3. Actuarial survival curve of the series (OS and FDS). 


\section{DISCUSSION}

$\mathrm{CC}$ is one of the most common malignancies in the world, and liver is the most frequent site of metastasis. Therefore, LM constitute a critical issue in the treatment of patients with CC. Complete resection of primary tumor and LM is the only option for improving prognosis of patients with CC and LM. 5-year OS in cases undergoing chemotherapy alone is 0 to $5 \%$ (Aloia et al., 2006). In contrast, if the primary lesion and metastases are radically resected, 5-year OS varied between $25 \%$ to $70 \%$ (Grundmann, 2011; Viganò et al., 2012; Slesser et al., 2013; Olsson et al.). Even though the order of procedures is still a matter of debate, different studies suggest that simultaneous resection is an effective therapy for patients with CC and LHM, in whom OS and DFS are not inferior to staged resection (Moug et al., 2010; Xu et al.; Grytsenko; Zhai et al.).

In a SR of studies published between 1999 and 2010, based on 60 studies, 5 and 10-year survival ranged from 16 $\%-74 \%$, and $9 \%-69 \%$ respectively; with a meta-relative risks by prognostic factor of node positive primary $1.6(95$ \%CI: $1.5 ; 1.7)$; carcinoembryonic antigen level, 1.9 (95 \% CI: 1.1; 3.2); extrahepatic disease, 1.9 (95 \% CI: 1.5; 2.4); poor tumor grade, 1.9 (95\%CI: 1.3; 2.7); positive margin, 2.0 (95 \%CI: 1.7; 2.5); >1 liver metastases, 1.6 (95\%CI: 1.4; $1.8)$; and $>3 \mathrm{~cm}$ tumor diameter, 1.5 (95\% $\%$ : $1.3 ; 1.8)$ (Kanas et al., 2012).

In a SR and network meta-analysis of 44 studies reporting on 10848 patients with CCSLM, cases undergoing simultaneous resection approach resulted in a higher risk of major morbidity and 30-day mortality. Pairwise and network meta-analysis showed a more favorable 5-year OS after simultaneous resection compared to 'liver-first' approach (OR: $0.25 ; 0.90, \mathrm{p}=0.02$ ), but not compared to 'bowel-first' approach (Ghiaslo et al., 2020).

In a SR that included 10 retrospective cohort studies and 502 patients (216 operated with minimally invasive surgery and 286 with open surgery), it was found that the surgical time, the frecuency and severity of postoperative complications did not show significant differences. Furthermore, overall and disease-free survival were equivalent for both techniques (Ye et al., 2019).

Novelty of the proposal: The novelty of the proposal is that it is a single-center casuistry of patients of a private health institution, generating evidence regarding results of CCSLM surgery; with comparable results with different series (Kanas et al.; Zhang et al., 2017; Ghiasloo et al., 2020; Olsson et al.; Zhai et al.).
Comment on observed results: Surgery is essential in the treatment of CCSLM and is considered curative when all macroscopic disease is removed, followed by the histological demonstration of the absence of neoplasia on the margins of the surgical specimen. Thus, $\mathrm{R} 0$ resection will be considered when in-block excision of the tumor with disease-free histological margins was performed (Olsson et al.).

Although reports of surgical mortality for CCSLM fluctuate between $1.5 \%$ and $9.0 \%$ (Olsson et al.), postoperative mortality was not recorded in this series.

POM of our series (31.2\%) is like others (Zhang et al.; Olsson et al.; Zhai et al.). On the other hand, the reports regarding anastomotic leakage in elective colectomies, fluctuate between $0 \%$ and $20 \%$ (Sciuto et al., 2018). This complication was verified in 2 cases $(12.5 \%)$.

Local recurrence was verified in $19.2 \%$ of cases, lower than reported after curative resection, which can reach $31 \%$ (Alnimer et al., 2017). There is evidence that this is associated with vascular or lymphatic permeation; to a few resected lymph nodes (less than 12); as well as the type of resection (R1 and R2) (Kojo et al., 2017).

In relation to 5-year OS and DFS, our data $(50.0 \%$ and $25.0 \%$ respectively), can be considered very suitable compared to what has already been published (Robinson et al.; Kanas et al.; Ferretti et al.; Zhang et al.; Grytsenko; Zhai et al.).

A great part of published experiences of simultaneous colon and liver resection for metastatic $\mathrm{CC}$ are retrospective case series, with open or laparoscopic access (Ferretti et al.; Zhang et al.; Abreu et al.; De Raffele et al.; Grytsenko; Olsson et al.; Zhai et al.), and recently with robotic assistance (Dwyer et al., 2018; Navarro et al., 2019; McGuirk et al., 2021).

Despite there are enough evidence that support that chemotherapy can be associated with significant changes to the hepatic parenchyma with subsequent increased risk of morbidity and mortality in the perioperative period (in direct relation with neoadyuvant chemotherapy regimens) (Robinson et al.; Zhai et al.), all patients received chemotherapy strategy, because, there are enough evidence that support the fact that improve OS and DFS (Ferretti et al.; Ihnát et al.; Bogach et al., 2020; Zhai et al.)

Unfortunately, mostly of existent evidence is based in retrospective studies and some meta-analysis of it. And although randomized controlled trials may be difficult to perform in this patients, prospective algorithm-based 
observational studies with focus on management strategies could be a way forward to increase evidence level to decision-make.

Limitations of the study: Among the limitations, it should be noted that this is a small series, in which all patients underwent surgery by the same surgeon. On the other hand, in the last cases, the follow-up is still brief. Moreover, always in this type of series there is the probability of occurrence of measurement and confusion biases (Manterola \& Otzen, 2015).

\section{CONCLUSIONS}

By way of conclusion, it can be stated that the results verified in this series, in terms of OS, DFS, POM and mortality in patients with CCSLM surgery, are comparable to previous published series.

MANTEROLA, C. \& CLAROS, N. Resección simultánea por cáncer de colon y metástasis hepáticas sincrónicas. Serie de casos con seguimiento. Int. J. Morphol., 39(6):1763-1768, 2021.

RESUMEN: El tratamiento del cáncer de colon (CC) con metástasis hepática sincrónica (MHS), tiene un tratamiento controvertido aún. El objetivo de este estudio fue analizar la experiencia unicéntrica en el tratamiento de pacientes con CC y MHS simultáneo, en términos de supervivencia global (SG) y supervivencia libre de enfermedad (SLE). Serie de casos retrospectiva consecutiva, de pacientes con CC y MHS sometidos a cirugía simultánea, en Clínica RedSalud Mayor Temuco, entre 2007 y 2021. Las variables de resultado fueron SG y SLE. Otras variables de interés fueron la morbilidad postoperatoria (MPO), tiempo quirúrgico, estancia hospitalaria y mortalidad. Se utilizó estadística descriptiva (medidas de tendencia central y dispersión) y se estimó supervivencia aplicando curvas de Kaplan Meier. Se operaron 16 pacientes (10 mujeres y 6 hombres), con mediana de edad de 61 años. La localización más frecuente fue ciego-colon derecho $(37,5 \%)$. En todos los casos se practicó algún tipo de resección hepática (hepatectomía conservadora o resección anatómica). La mediana del tiempo quirúrgico y la estancia hospitalaria fueron de $150 \mathrm{~min}$ y 5 días respectivamente. La MPO fue del 31,2\% (5 casos), principalmente Clavien \& Dindo I y II (hubo $12,5 \%$ de reintervenciones). Con una mediana de seguimiento de 52 meses. La SG a 1,3 y 5 años fue $100 \%, 62,5 \%$ y $50,0 \%$, respectivamente. Por otro lado, la SLE a 1,3 y 5 años fue $75,0 \%, 43,8 \%$ y 25,0 $\%$, respectivamente. La serie no tuvo mortalidad. La SG, SLE, MPO y la mortalidad fueron similares a otras series. La resección simultánea de CC y SLM es agresiva, pero no compromete los resultados oncológicos.

PALABRAS CLAVE: Cáncer de colon; cáncer de sigmoides; Metástasis hepáticas; Resección hepática.

\section{REFERENCES}

Abreu, P.; Ferreira, R.; Bussyguin, D. S.; DaCás, E.; Venkatasamy, V. V.; Tomasich, F. D. S. \& Szutan, L. A. Liver resections for metastasis: surgical outcomes of a single center academic institution. BMC Surg., 20(1):254, 2020.

Alnimer, Y.; Ghamrawi, R.; Aburahma, A.; Salah, S.; Rios-Bedoya, C. \& Katato. K. Factors associated with short recurrence-free survival in completely resected colon cancer. J. Community Hosp. Intern. Med. Perspect., 7(6):341-6, 2017.

Aloia, T. A.; Vauthey, J. N.; Loyer, E. M.; Ribero, D.; Pawlik, T. M.; Wei, S. H.; Curley, S. A.; Zorzi, D. \& Abdalla, E. K. Solitary colorectal liver metastasis: Resection determines outcome. Arch. Surg., 141(5):460-6, 2006

Bogach, J.; Wang, J.; Griffiths, C.; Parpia, S.; Saskin, R.; Hallet, J.; Ruo, L.; Simunovic, M. \& Serrano, P. E. Simultaneous versus staged resection for synchronous colorectal liver metastases: A populationbased cohort study. Int. J. Surg., 74:68-75, 2020.

Clavien, P. A; Barkun, J.; de Oliveira, M. L.; Vauthey, J. N.; Dindo, D.; Schulick, R. D.; de Santibañes, E.; Pekolj, J.; Slankamenac, K.; Bassi, C.; et al. The Clavien-Dindo classification of surgical complications: five-year experience. Ann. Surg., 250(2):187-96, 2009.

De Raffele, E.; Mirarchi, M.; Cuicchi, D.; Lecce, F.; Casadei, R.; Ricci, C.; Selva, S. \& minni, F. Simultaneous colorectal and parenchymalsparing liver resection for advanced colorectal carcinoma with synchronous liver metastases: Between conventional and miniinvasive approaches. World J. Gastroenterol., 26(42):6529-55, 2020.

Dwyer, R. H.; Scheidt, M. J.; Marshall, J. S. \& Tsoraides, S. S. Safety and efficacy of synchronous robotic surgery for colorectal cancer with liver metastases. J. Robot. Surg., 12(4):603-6, 2018.

Ferlay, J.; Colombet, M.; Soerjomataram, I.; Mathers, C.; Parkin, D.M.; Bray, F.; Piñeros, M.; Znaor, A. \& Bray, F. Estimating the global cancer incidence and mortality in 2018: GLOBOCAN sources and methods. Int. J. Cancer, 144(8):1941-53, 2019.

Ferretti, S.; Tranchart, H.; Buell, J. F.; Eretta, C.; Patriti, A.; Spampinato, M. G.; Huh, J. W.; Vigano, L.; Han, H. S.; Ettorre, G. M.; et al. Laparoscopic simultaneous resection of colorectal primary tumor and liver metastases: results of a multicenter international study. World J. Surg., 39(8):2052-60, 2015.

Ghiasloo, M.; Pavlenko, D.; Verhaeghe, M.; Van Langenhove, Z.; Uyttebroek, O.; Berardi, G.; Troisi, R. I. \& Ceelen, W. Surgical treatment of stage IV colorectal cancer with synchronous liver metastases: A systematic review and network meta-analysis. Eur. J. Surg. Oncol., 46(7):1203-13, 2020.

Grundmann, R. T. Current state of surgical treatment of liver metastases from colorectal cancer. World J. Gastrointest. Surg., 3(12):183-96, 2011.

Grytsenko, S. Simultaneous surgical treatment of patients with colorectal cancer and liver metastasis. Georgian Med. News., (301):50-3, 2020.

Helsinki Statement. WMA Declaration of Helsinki - Ethical Principles for Medical Research Involving Human Subjects. Fortaleza, 64th WMA General Assembly, 2013. Available from: https://www.wma.net/ policies-post/wma-declaration-of-helsinki-ethical-principles-formedical-research-involving-human-subjects.

Ihnát, P.; Vávra, P. \& Zonc`a, P. Treatment strategies for colorectal carcinoma with synchronous liver metastases: Which way to go? World J. Gastroenterol., 21(22):7014-21, 2015.

Itriago, L.; Silva, N. \& Cortes, G. Epidemiology of cancer in Chile and worldwide: present and future. Rev. Med. Clin. Condes, 24(4):53152, 2013.

Kanas, G.P.; Taylor, A.; Primrose, J.N.; Langeberg, W.J.; Kelsh, M.A.; Mowat, F.S.; Alexander, D. D.; Choti, M. A. \& Poston, G. Survival after liver resection in metastatic colorectal cancer: review and metaanalysis of prognostic factors. Clin. Epidemiol., 4:283-301, 2012. 
Kojo, K.; Katoh, H.; Naito, M.; Yamashita, K.; Nakamura, T.; Sato, T.; Yamanashi, T. \& Watanabe, M. Lymphatic permeation predicts systemic recurrence in combination with vascular involvement in laparoscopically resected N0 colon cancer. Am. Surg., 83(12):1394400, 2017.

Kwaan, J. R.; Al-Refaie, W. B.; Parsons, H. M.; Chow, C. J.; Rothenberger, D. A. \& Habermann, E. B. Are right-sided colectomy outcomes different from left-sided colectomy outcomes? Study of patients with colon cancer in the ACS NSQIP database. JAMA Surg., 148(6):50410, 2013.

Lykoudis, P. M.; O’Reilly, D.; Nastos, K. \& Fusai, G. Systematic review of surgical management of synchronous colorectal liver metastases. Br. J. Surg., 101(6):605-12, 2014.

Manterola, C. \& Claros, N. Results of surgical treatment of uncomplicated colon cancer. Case series with follow-up. Int. J. Morphol., 39(4):1171$5,2021$.

Manterola, C. \& Otzen, P. Checklist for reporting results using observational descriptive studies as research designs: the MInCir Initiative. Int. J. Morphol., 31(1):72-6, 2017.

Manterola, C. \& Otzen, T. Bias in clinical research. Int. J. Morphol., 33(3):1156-64, 2015.

McGuirk, M.; Gachabayov, M.; Rojas, A.; Kajmolli, A.; Gogna, S.; Gu, K. W.; Qiuye, Q. \& Dong, X. D. Simultaneous robot assisted colon and liver resection for metastatic colon cancer. JSLS, 25(2):e2020.00108, 2021.

Moug, S. J.; Smith, D.; Leen, E.; Roxburgh, C. \& Horgan, P. G. Evidence for a synchronous operative approach in the treatment of colorectal cancer with hepatic metastases: A case matched study. Eur. J. Surg. Oncol., 36(4):365-70, 2010.

Navarro, J.; Rho, S. Y.; Kang, I.; Choi, G. H. \& Min, B. S. Robotic simultaneous resection for colorectal liver metastasis: feasibility for all types of liver resection. Langenbecks Arch. Surg., 404(7):895-908, 2019.

Olsson, L. B.; Buchli, C.; Villard, C. \& Nilsson, P. J. Differences in management and outcome for colon and rectal carcinoma with synchronous liver metastases: a population-based cohort study. Colorectal Dis., 23(4):860-7, 2021.

Renouf, D. J.; Woods, R.; Speers, C.; Hay, J.; Phang, P. T.; Fitzgerald, C. \& Kennecke, H. Improvements in 5-year outcomes of stage II/III rectal cancer relative to colon cancer. Am. J. Clin. Oncol., 36(6):558-64, 2013.

Robinson, S.; Manas, D. M.; Pedley, I.; Mann, D. \& White, S. A. Systemic chemotherapy and its implications for resection of colorectal liver metastasis. Surg. Oncol., 20(2):57-72, 2011.

Sciuto, A.; Merola, G.; De Palma, G. D.; Sodo, M.; Pirozzi, F.; Bracale, U. M. \& Bracale, U. Predictive factors for anastomotic leakage after laparoscopic colorectal surgery. World J. Gastroenterol., 24(21):224760, 2018.

Silberhumer, G. R.; Paty, P. B.; Temple, L. K.; Araujo, R. L.; Denton, B.; Gonen, M.; Nash, G. M.; Allen, P. J.; DeMatteo, R. P.; Guillem, J.; et al. Simultaneous resection for rectal cancer with synchronous liver metastasis is a safe procedure. Am. J. Surg., 209(6):935-42, 2015.

Slesser, A. A.; Simillis, C.; Goldin, R.; Brown, G.; Mudan, S. \& Tekkis, P. P. A meta-analysis comparing simultaneous versus delayed resections in patients with synchronous colorectal liver metastases. Surg. Oncol., 22(1):36-47, 2013.

Viganò, L.; Russolillo, N.; Ferrero, A.; Langella, S.; Sperti, E. \& Capussotti, L. Evolution of long-term outcome of liver resection for colorectal metastases: Analysis of actual 5-year survival rates over two decades. Ann. Surg. Oncol., 19(6):2035-44, 2012.

Xu, J.; Qin, X.; Wang, J.; Zhang, S.; Zhong, Y.; Ren, L.; Wei, Y.; Zeng, S.; Wan, D.; Zheng, S.; et al. Chinese guidelines for the diagnosis and comprehensive treatment of hepatic metastasis of colorectal cancer. J. Cancer Res. Clin. Oncol., 137(9):1379-96, 2011.

Ye, S. P.; Qiu, H.; Liao, S. J.; Ai, J. H. \& Shi, J. Mini-invasive vs open resection of colorectal cancer and liver metastases: A meta-analysis. World J. Gastroenterol., 25(22):2819-32, 2019.
Zhai, S.; Sun, X.; Du, L.; Chen, K.; Zhang, S.; Shi, Y. \& Yuan, F. Role of surgical approach to synchronous colorectal liver metastases: a retrospective analysis. Cancer Manag. Res., 13:3699-711, 2021.

Zhang, Y. F.; Mao, R.; Chen, X.; Zhao, J. J.; Bi, X. Y.; Li, Z. Y.; Zhou, J. G.; Zhao, H.; Huang, Z.; Sun, Y. K.; et al. Prognostic Analysis of 102 Patients with Synchronous Colorectal Cancer and Liver Metastases Treated with Simultaneous Resection. Chin. Med. J. (Engl)., 130(11):1283-9, 2017.

\author{
Corresponding author: \\ Dr. Carlos Manterola \\ Department of Surgery and CEMyQ \\ Universidad de La Frontera \\ Temuco \\ CHILE
}

E-mail: carlos.manterola@ufrontera.cl

Received: 13-09-2021

Accepted: 11-10-2021 